Key efficacy results of lifitegrast ophthalmic solution $5.0 \%$ across 12 -week multicenter randomized controlled trials (ITT population with LOCF)

\begin{tabular}{|c|c|c|}
\hline Study & Symptom endpoint & Sign endpoint \\
\hline Phase 2 & $\begin{array}{l}\text { Visual-related function subscale } \\
\text { (secondary, change from baseline to } \\
\text { day } 84 \text { ): TE } 0.37 \text {, nominal } P=0.0394 \text {. }\end{array}$ & $\begin{array}{l}\text { - Primary endpoint of ICSS at day } 84 \\
\text { not met. } \\
\text { - ICSS (secondary, change from } \\
\text { baseline to day } 84 \text { ): TE } 0.35 \text {, nominal } \\
P=0.0209 \text {. }\end{array}$ \\
\hline OPUS-1 & $\begin{array}{l}\text { - Coprimary endpoint of change from } \\
\text { baseline to day } 84 \text { on visual-related } \\
\text { function subscale not met. }\end{array}$ & $\begin{array}{l}\text { - ICSS (co-primary, change from } \\
\text { baseline to day } 84 \text { ): TE } 0.24 \text {, } \\
P=0.0007 \text {. }\end{array}$ \\
\hline OPUS-2 & $\begin{array}{l}\text { EDS (VAS; co-primary, change from } \\
\text { baseline to day } 84 \text { ): TE } 12.61 \text {, } \\
P<0.0001 .\end{array}$ & $\begin{array}{l}\text { - Coprimary endpoint of change from } \\
\text { baseline to day } 84 \text { in ICSS not met. }\end{array}$ \\
\hline OPUS-3 & $\begin{array}{l}\text { EDS (VAS; primary, change from } \\
\text { baseline to day } 84 \text { ): TE } 7.16 \text {, } \\
P=0.0007 \text {. }\end{array}$ & $\begin{array}{l}\text { - ICSS (ad hoc, change from baseline } \\
\text { to day } 84 \text { ): TE } 0.17 \text {, nominal } \\
P=0.0144 \text {. }\end{array}$ \\
\hline
\end{tabular}

Eye dryness score (EDS; visual analogue scale [VAS]); ICSS, inferior corneal staining score; ITT,

intention-to-treat; LOCF, last observation carried forward; $T E$, treatment effect.

$P=0.0007$ ), and OPUS-3 (ad hoc; 0.17 , nominal $P=0.0144$ ). LIF reduced EDS (VAS) versus PBO in OPUS-2 (co-primary; 12.61, $P<0.0001$ ) and OPUS-3 (primary; 7.16, $P=0.0007$ ). The OPUS-1 co-primary symptom endpoint of visualrelated function subscale, and the OPUS-2 co-primary sign endpoint of ICSS, did not achieve statistical significance. In the pooled safety analysis, total exposure was 415.65 person-years for LIF, and 332.15 person-years for PBO. Adverse events were mostly mild or moderate in severity. There were no serious ocular treatment-emergent adverse events (TEAEs) and withdrawals due to TEAEs were infrequent (LIF, 7.0\%; PBO, 2.6\%).

Conclusions: LIF improved signs and symptoms of DED in adults with DED and appeared to be well tolerated with no serious ocular TEAEs reported.

References:

[1] DEWS. Ocul Surf. 2007;5:75-92.

[2] Fujita M et al. Am J Ophthalmol. 2005;140:808-13.

[3] Patel SJ, Lundy DC. Am Fam Physician. 2002:66:991-8.

Acknowledgements: This study was sponsored by SARcode Bioscience (now a wholly owned subsidiary of Shire PLC) and Shire Development LLC.

Disclosure of Interest: C. Baudouin Consultant for: Alcon Laboratories, Inc., Allergan, Dompé, Horus Pharma, Santen Inc., Thea Pharmaceuticals, M. DarvishZargar Consultant for: Allergan, Novartis, Abbott Medical Optics, E. Holland Grant/research support from: Alcon Laboratories Inc., Allergan, Mati Therapeutics, Omeros, PRN, Senju Pharaceuticals, Consultant for: Alcon Laboratories Inc., Allergan, Bausch \& Lomb, Kala Pharmaceuticals, Mati Therapeutics, Omeros, PRN, RPS, Senju Pharaceuticals, Shire/SARcode, TearLab, TearScience, Speakers bureau: Alcon Laboratories Inc., Allergan, Bausch \& Lomb, Omeros, Senju Pharaceuticals, Shire/SARcode, TearScience, C. Chan Grant/research support from: Allergan, Bausch and Lomb, TearLab, Consultant for: Allergan, Bausch \& Lomb, Alcon Labs Inc., TearScience, K. Nichols Grant/research support from: Kala Pharmaceuticals, Shire PLC, TearScience, Vistakon, Consultant for: Allergan, InSite Vision Inc., Kala Pharmaceuticals, Parion Sciences, Santen, ScienceBased Health, Shire PLC/SARcode, J. Tauber Consultant for: Allergan, Bausch \& Lomb, Shire PLC, Senju Pharaceuticals, Speakers bureau: Shire/SARcode, A. Raychaudhuri Employee of: Shire PLC (at the time of the study), M. Roy Employee of: Shire PLC, A. Shojaei Employee of: Shire PLC

DOI: 10.1136/annrheumdis-2017-eular.5890

\section{LB0002 48 WEEK COMPLETE REMISSION OF ACTIVE LUPUS NEPHRITIS WITH VOCLOSPORIN}

V. Dobronravov ${ }^{1}$, M.A. Dooley ${ }^{2}$, S.A. Haq $^{3}$, I. Adzerikho ${ }^{4}$, O. Bugrova ${ }^{5}$, D. Isenberg ${ }^{6}, F$. Houssiau ${ }^{7}, N$. Solomons ${ }^{8}$, R. Huizinga ${ }^{8}$ on behalf of AURA-LV Study Group. ${ }^{1}$ Pavlov First St. Petersburg State Medical University, St. Petersberg, Russian Federation; ${ }^{2}$ UNC, Chapel Hill, United States; ${ }^{3}$ Bangabandhu Sheikh Mujib Medical University (BSMMU), Dhaka, Bangladesh; ${ }^{4}$ Minsk Regional Clinical Hospital, Minsk, Belarus; ${ }^{5}$ Orenburg Regional Clinical Hospital, Orenburg, Russian Federation; ${ }^{6}$ University College Hospital, London, United Kingdom; ${ }^{7}$ Université catholique de Louvain, Brussels, Belgium; ${ }^{8}$ Aurinia Pharmaceuticals, Victoria, Canada

Background: Voclosporin (VCS) is a novel CNI intended for use in the treatment of autoimmune diseases such as lupus nephritis (LN). VCS's unique structure allows for less pharmacokinetic-pharmacodynamic variability and a potentially improved safety profile compared to other CNls.

Objectives: Achievement of complete remission (CR) as assessed at week 24 (primary objective) and assessment of the efficacy over 48 weeks (secondary objective), with 2 doses of VCS (low dose VCS: $23.7 \mathrm{mg} \mathrm{BID}$ and high dose VCS: $39.5 \mathrm{mg}$ BID) vs. placebo in subjects with active LN.
Methods: The double blind placebo controlled AURA study enrolled 265 subjects with active LN in 20 countries. Patients were randomized into 3 arms (placebo, low dose VCS or high dose VCS) in addition to MMF $2 \mathrm{~g} /$ day and steroids (with rapid tapering). CR was defined as a confirmed urine protein/creatinine ratio (UPCR) of $\leq 0.5 \mathrm{mg} / \mathrm{mg}$ using first morning void and confirmed estimated glomerular filtration rate (eGFR, CKD-EPI equation) $\geq 60 \mathrm{~mL} / \mathrm{min} / 1.73 \mathrm{~m}^{2}$ or no decrease from baseline in eGFR of $>20 \%$ in the presence of low dose steroids. Partial remission (PR) was defined as a $50 \%$ reduction in UPCR. UPCR assessments were made at each visit, together with biomarker data at regular intervals.

Results: We now present the 48 week data showing improved CR rates over the 24 week data. The rate of CR was significantly higher in the low dose VCS compared to the control group (32.6\% vs. $19.3 \%$; OR: $2.03, p=0.045$ ) at 24 weeks. It was $27.3 \%$ in the high dose VCS group ( $p=N S$ ). Both doses of voclosporin demonstrated superiority to control using time to CR, PR $(50 \%$ reduction in proteinuria) and time to PR.

At 48 weeks, $23.9 \%$ of patients on the control arm achieved CR comparted to $49.4 \%$ low dose (OR: $3.21, p<0.001$ ) and $39.8 \%$ high dose (OR: $2.10, p<0.026$ ). Over $92 \%$ of subjects experienced at least one adverse event (AE) with the most common two being infections (58\% low, $66 \%$ high and $55 \%$ placebo) and GI disorders ( $43 \%$ low, $52 \%$ high and $38 \%$ placebo). The overall rate of serious adverse events (SAEs) was numerically higher in both voclosporin groups $(28 \%$ low, $25 \%$ high, $19 \%$ placebo) with the nature of SAEs consistent with those observed in patients with highly active LN. Most deaths occurred in the first 2 months and were: low dose (infection3, ARDS2, thrombotic3, cardiac tamponade, pulmonary hemorrhage), high dose (infection, PE) and control (CVA). All were considered unrelated to drug exposure by the investigators. 3 additional deaths occurred in placebo patients after the conclusion of the 48 weeks of treatment.
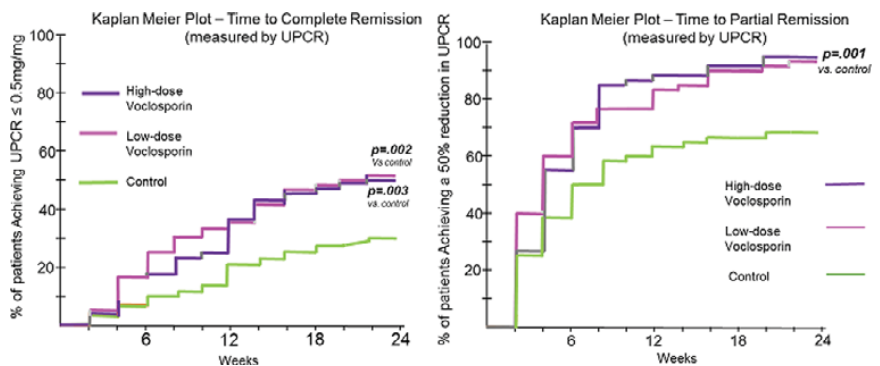

Conclusions: The AURA-LV study is the first global study demonstrating the beneficial effect of VCS, in combination with MMF and steroids, in the treatment of $L N$. Remission rate was rapid. VCS treatment resulted in increasing CR and PR seen by week 6 despite rigorous steroid taper (mean steroid dose $4 \mathrm{mg}$ at week 16). Adverse events were higher in the treated patient group with the nature in keeping with immunosuppression. These promising data will be used to plan subsequent studies of voclosporin in LN.

Acknowledgements: This data was submitted on behalf of the AURA-LV study investigators.

Disclosure of Interest: V. Dobronravov Grant/research support from: Aurinia Pharmaceuticals Inc., M. A. Dooley Grant/research support from: Aurinia Pharmaceuticals Inc., S. A. Haq Grant/research support from: Aurinia Pharmaceuticals Inc., I. Adzerikho Grant/research support from: Aurinia Pharmaceuticals Inc., O. Bugrova Grant/research support from: Aurinia Pharmaceuticals Inc., D. Isenberg: None declared, F. Houssiau: None declared, N. Solomons Shareholder of: Aurinia Pharmaceuticals Inc., Employee of: Aurinia Pharmaceuticals Inc., R. Huizinga Shareholder of: Aurinia Pharmaceuticals Inc., Employee of: Aurinia Pharmaceuticals Inc.

DOI: 10.1136/annrheumdis-2017-eular.7079

\section{FRIDAY, 16 JUNE 2017 Axial spondyloarthritis from risk factor to clinical outcomes}

\section{OP0238 MEASUREMENT OF SPINAL MOBILITY IN AXIAL SPONDYLOARTHRITIS USING INERTIAL SENSORS: RELIABILITY AND VALIDATION PRELIMINARY RESULTS}

F.J. Mata-Perdigon ${ }^{1}$, I.R. Martínez Sanchez ${ }^{2}$, J.L. Garrido-Castro ${ }^{1}$, C. González-Navas ${ }^{1}$, L.M. Fernandez-Ahumada ${ }^{2}$, D.A. Gomez ${ }^{1}$,

V.C. Perez-Guijo ${ }^{1}$, P. Font-Ugalde ${ }^{1}$, E. Collantes-Estevez ${ }^{1} .{ }^{1}$ Maimonides Institute for Biomedical Research of Cordoba; ${ }^{2}$ University of Cordoba, Cordoba, Spain

Background: Axial spondyloarthritis (axSpA) is a chronic rheumatic disease that causes reduction of mobility in the patients' spine. There are several indices to analyze this mobility: BASMI, which lacks precision and sensitivity to change according to different authors, and UCOASMI (1) based on motion capture, which needs extensive resources that limit its practical applicability. Inertial measurement unit sensors (IMU) give, in real time, the 3D orientation of any anatomical place 